\title{
Experimental conditions affect the site of tetrazolium violet reduction in the electron transport chain of Lactococcus lactis
}

\begin{abstract}
Correspondence
Mireille Yvon

mireille.yvon@jouy.inra.fr
\end{abstract}

Received 30 March 2009

Revised 26 May 2009

Accepted 7 June 2009

\author{
Sybille Tachon, ${ }^{1}$ Damien Michelon, ${ }^{2}$ Emilie Chambellon, ${ }^{1}$ \\ Monique Cantonnet, ${ }^{1}$ Christine Mezange, ${ }^{1}$ Lucy Henno, ${ }^{1}$ Rémy Cachon ${ }^{2}$ \\ and Mireille Yvon ${ }^{1}$ \\ ${ }^{1}$ INRA, UR 477 Biochimie Bactérienne, F-78350 Jouy-en-Josas, France \\ ${ }^{2}$ Laboratoire de Génie des Procédés Microbiologiques et Alimentaires, AgroSup Dijon - Université \\ de Bourgogne, INRA, 17 rue Sully, 21065 Dijon, France
}

\section{INTRODUCTION}

Tetrazolium salts are colourless compounds which become coloured when reduced to formazans. Traditionally used as indicators of cell metabolism in eukaryotes and prokaryotes, they function as artificial electron acceptors and thus

\footnotetext{
Abbreviations: CTC, 5-cyano-2,3-ditolyl tetrazolium chloride; INT, 2-(4iodophenyl)-3-(4-nitrophenyl)-5-phenyl-2H-tetrazolium chloride; MTS, 5-[3-(carboxymethoxy)phenyl]-3-(4,5-dimethyl-2-thiazolyl)-2-(4-sulfophenyl)-2H-tetrazolium inner salt; MTT, 2-(4,5-dimethyl-2-thiazolyl)-3,5diphenyl-2H-tetrazolium bromide; TTC, 2,3,5-triphenyl-2H-tetrazolium chloride; TV, 2,5-diphenyl-3-2-naphthyl tetrazolium chloride or tetrazolium violet; WST-1, sodium 5-(2,4-disulfophenyl)-2-(4-iodophenyl)-3(4-nitrophenyl)-2H-tetrazolium inner salt; WST-5, disodium 2,2'-dibenzothiazolyl-5,5'-bis[4-di(2-sulfoethyl)carbamoylphenyl]-3,3'-(3,3'-dimethoxy-4,4'-biphenylene) ditetrazolium salt; XTT, sodium 2,3-bis(2-methyloxy-4-nitro-5-sulfophenyl)-5-[(phenylamino)-carbonyl]-2H-tetrazolium inner salt; ETC, electron transport chain; LAB, lactic acid bacteria, $\mathrm{SOD}$, superoxide dismutase.
}

detect dehydrogenase activities. The production of coloured formazan is irreversible and can be quantified using spectrophotometry.

Two types of tetrazolium salts are used in the context of microbiological studies, either in nutritive media where cells are growing or in non-nutritive media where cells do not grow and are thus in a resting state. The first type includes MTT, INT, CTC, TTC and TV, which form waterinsoluble formazans (see the footnote on this page for the full names of the salts). These salts are positively charged and considered as cell permeable (Berridge et al., 2005). Their positive charge is thought to facilitate cellular uptake due to the membrane potential. They are generally used as indicators of cell redox activity in order to test resistance to solvents (Hayashi et al., 2003), drug susceptibility (Raut et al., 2008) or specific substrate utilization (Bochner \& Savageau, 1977; Lin et al., 2008). They also enable the discrimination of viable cells in populations of respiring 
bacteria (Rodriguez et al., 1992) and anaerobic bacteria (Bhupathiraju et al., 1999; Smith \& McFeters, 1997). They can help to enumerate microbial colonies in solid culture media, and to detect microbial contamination in food (Beloti et al., 1999). These salts have also been used as indicators of cell surface redox potential (Sollod et al., 1992) and extracellular redox activity (Griebe et al., 1997). Tetrazolium salts of the second type, which include XTT, MTS, WST-1 and WST-5, form water-soluble formazans. They are negatively charged and largely cell impermeable. They are generally used in conjunction with intermediate electron acceptors (quinones or their derivatives) that facilitate reduction reactions. These salts have been used in microplate assays to measure bacterial proliferation (Tsukatani et al., 2008) and in colorimetric assays to test antimicrobial susceptibility (Tsukatani et al., 2008; Tunney et al., 2004).

The mechanisms of tetrazolium salt reduction are well documented in eukaryotes, but have been little investigated in bacteria. Studies on eukaryotic cells have shown that reduction can occur extracellularly or intracellularly, depending on the capacity of the tetrazolium salt to penetrate into the cell. Extracellular reduction involves the membrane electron transport chain (ETC), while intracellular reduction involves dehydrogenases (Bernas \& Dobrucki, 1999; Berridge et al., 2005). In prokaryotes, the main studies have concerned the Gram-negative respiring bacterium Escherichia coli. Smith \& McFeters (1997) used a liquid test with resting cells and various inhibitors of the ETC to show that CTC and INT were mainly reduced before ubiquinone by two ETC enzymes, succinate dehydrogenase and NADH dehydrogenase. By contrast, Bochner \& Savageau (1977) reported that a mutant of $E$. coli that was unable to synthesize ubiquinone was deficient in TTC reduction in a plate test with growing cells, indicating that TTC reduction occurs at or after the coenzyme-quinone site of the ETC. These different conclusions may be due to differences in the cell permeability of the tetrazolium salts used. However, the three salts, CTC, INT and TTC, are all supposed to enter cells. Another explanation is that the ability of the tetrazolium salt to enter cells is dependent on the experimental conditions employed, i.e. cells growing on a solid medium in one case and resting cells in a liquid medium in the other. The ability of bacteria to reduce tetrazolium salts is strongly species-dependent. Beloti et al. (1999) showed that most of the bacteria isolated from pasteurized milks that did not reduce TTC were Grampositive. On the other hand, Tsukatani et al. (2008) showed that Gram-positive bacteria generally reduced tetrazolium salts that form water-soluble formazan better than Gramnegative bacteria. Only a few uses of tetrazolium salts have been reported for lactic acid bacteria (LAB), probably because the acid produced by LAB inhibits tetrazolium salt reduction. In this respect, TTC was used to distinguish Lactococcus lactis subsp. cremoris from L. lactis subsp. lactis in a medium containing arginine because only $L$. lactis subsp. lactis produces ammonia, which can counteract the acid inhibition of the dye reduction (Turner et al., 1963). Also, a recent study using tetrazolium salts that form water-soluble formazans showed that LAB were less efficient in reducing WST-5 than other Gram-positive bacteria, but reduced the dye as well as Gram-negative bacteria (Tsukatani et al., 2008).

L. lactis is widely used as a starter in the dairy industry and is considered as a model of lactic acid bacteria. This acidifying Gram-positive bacterium has been shown to exert a strong reducing activity (Brasca et al., 2007). It does not respire, because its haem biosynthetic pathway is incomplete. However, L. lactis possesses all the components of the ETC, i.e. membrane dehydrogenases (Brooijmans et al., 2007; Gaudu et al., 2002; Melo et al., 2004), menaquinones (Morishita et al., 1999; Rezaiki et al., 2008) and a unique cytochrome oxidase. Cytochrome $d$ oxidase, encoded by $c y d A$ and $c y d B$, is only active when haem is provided in the growth medium (Bolotin et al., 2001; Wegmann et al., 2007). It is noteworthy that L. lactis menaquinones were recently shown to reduce extracellular divalent cations as well as oxygen (Rezaiki et al., 2008). Because the reaction reflects electron transfers, lactococci are certainly able to reduce tetrazolium salts.

Despite the frequent use of tetrazolium salts in microbiology, the mechanisms of tetrazolium salt reduction have not clearly been identified in bacteria, and the impact of experimental conditions has never to our knowledge been investigated. This lack of knowledge may lead to the incorrect use and interpretation of tetrazolium salt tests. To address scientific questions using the most appropriate salt and method, it is therefore necessary to clarify the mechanisms and sites of reduction for each tetrazolium salt.

During the present study, we investigated the mechanisms of TV reduction by L. lactis. TV is the constitutive dye of Biolog microplates, which have been used to achieve numerous research discoveries in microbiology (Bochner, 1989; Bochner \& Savageau, 1977; Bochner et al., 2001, 2008). TV is a monotetrazolium salt that is reduced to a water-insoluble formazan, like MTT, CTC, INT and TTC. It is more difficult to reduce than MTT, CTC and INT, but more easily reduced than TTC (Sollod et al., 1992). The intracellular reduction of MTT, INT, CTC and TTC has been demonstrated (Bernas \& Dobrucki, 1999, 2000, 2002, 2004; Berridge \& Tan, 1993; Berridge et al., 2005), while the localization of TV reduction has not.

To our knowledge, questions concerning tetrazolium salt reduction have hitherto essentially been addressed using physiological approaches. Only one publication has investigated the cellular site of tetrazolium dye reduction using non-lethal mutants covering the whole genome in the eukaryote Saccharomyces cerevisiae (Herst et al., 2008). Here, we investigated the mechanism of TV reduction by the prokaryote L. lactis using a mutagenesis approach under the two experimental conditions generally employed in microbiology, i.e. on a solid medium with growing cells 
(plate test) and in a liquid medium with resting cells (liquid test).

\section{METHODS}

Bacterial strains and growth conditions. L. lactis subsp. cremoris TIL46 (wild-type strain) is derived from L. lactis NCDO763 cured of its $2 \mathrm{~kb}$ plasmid (National Collection of Food Bacteria; now part of the NCIMB, Aberdeen, UK). The TIL46 ldh-negative mutant, TIL380, had previously been constructed by single cross-over (Chambellon et al., 2009). Lactococcal strains were grown at $30{ }^{\circ} \mathrm{C}$ either in $\mathrm{M} 17$ broth (Difco) supplemented with lactose (LM17) or glucose (GM17) at a final concentration of $0.5 \%(\mathrm{w} / \mathrm{v})$, or in skimmed milk (Lescure, Surgères, France). When required, an antibiotic (tetracycline or erythromycin) was added at a final concentration of $5 \mu \mathrm{g} \mathrm{ml} l^{-1}$. Bacterial growth was estimated by measuring $\mathrm{OD}_{480}$ (Uvikon XL spectrophotometer, Biotek Instruments, path length $1 \mathrm{~cm}$ ), after the dilution of $0.1 \mathrm{ml}$ culture with $0.9 \mathrm{ml}$ EDTA $\left(5 \mathrm{~g} \mathrm{l}^{-1}, \mathrm{pH} 12.0\right)$ in the case of milk culture.

Plate assays with tetrazolium salts. The base medium used to test the ability of strains to reduce tetrazolium salts consisted of 2.5 vols skimmed milk (Lescure) and 1 vol. $3 \%$ (w/v) agar solution (MilkAgar). The tetrazolium salt TV, MTT, TTC or INT (Sigma) was added to MilkAgar at a final concentration of $0.02 \mathrm{mg} \mathrm{ml}^{-1}$. Two microlitres of an overnight GM17 culture was spotted on a MilkAgar plate containing the appropriate salt and incubated overnight at $30^{\circ} \mathrm{C}$.

DNA manipulations. DNA extractions, PCR, plasmid preparation and sequencing were performed as described by Sambrook \& Russell (2001). DNA restriction and modification enzymes were purchased from New England Biolabs and used as recommended by the supplier. The primers used in this study were synthesized by Eurogentec and are listed in Table 1. L. lactis electrocompetent cells were prepared and transformed as described by Holo \& Nes (1989). Plasmid DNA was prepared according to the method of O'Sullivan \& Klaenhammer (1993). PCR amplifications were carried out with an Applied Biosystems DNA thermal cycler 2720, using Taq DNA polymerase (MP Biomedicals) or DNA polymerase Phusion (High-Fidelity PCR Master Mix, Finnzymes). Samples for sequencing were prepared using the PRISM Ready Reaction Dye Deoxy terminator cycle sequencing kit (Applied Biosystems) and sequences were determined with an automatic sequencer (Abi Prism 310 DNA sequencer, Applied Biosystems).
Construction of a random mutant library. A random insertion mutant library was constructed in L. lactis TIL46 using the thermosensitive plasmid $\mathrm{pG}^{+}$host 9 : : ISS1, as described by Maguin et al. (1992, 1996). About 8500 integrants were selected on LM17Ery, because it was calculated that 8000 mutants were needed so that $95 \%$ of the genes would be represented by an integrant (Bolotin et al., 2001; Smit et al., 2005). They were organized in 96-well microtitre plates containing $100 \mu \mathrm{L}$ LM17 supplemented with erythromycin, and grown overnight at $30{ }^{\circ} \mathrm{C}$. Before storage at $-80{ }^{\circ} \mathrm{C}, 200 \mu \mathrm{LM} 17$ containing glycerol was added to each well to obtain a final glycerol concentration of $27 \%(\mathrm{v} / \mathrm{v})$. Random integration was verified by Southern blotting using the ECL direct nucleic acid labelling and detection system kit (GE Healthcare). For this purpose, total DNAs of 45 mutants from the library were extracted and digested with either EcoRI or HindIII. The fragments obtained were separated on a $0.7 \%$ agarose gel, blotted, and hybridized with HindIII-cut, digoxigeninlabelled $\mathrm{pG}^{+}$host 9 as the probe (Maguin et al., 1992). Transposition was shown to be random, but about $80 \%$ of the tested mutants displayed a tandem insertion.

Screening of the mutant library for TV-reducing ability. Mutants were spotted on MilkAgar plates containing TV (MilkAgarTV), using a 96-pin replicator, and incubated at $30{ }^{\circ} \mathrm{C}$ for $24 \mathrm{~h}$. A violet coloration is indicative of TV reduction to formazan. Mutants that reduced TV more or less than the wild-type (WT) strain TIL46 were selected. To verify the difference in TV reduction between the selected mutants and WT, the TV reduction and growth of each selected mutant were tested individually. Growth was verified on MilkAgarBP plates containing a $\mathrm{pH}$ indicator, bromocresol purple (BP). Two microlitres of overnight cultures of each mutant in LM17 supplemented with erythromycin were spotted on MilkAgarTV and MilkAgarBP and incubated at $30{ }^{\circ} \mathrm{C}$ for $24 \mathrm{~h}$.

Determination of disrupted genes in the selected mutants. To determine the pG+host $9:$ ISS1 integration site in the selected mutants, total DNA was extracted, digested with EcoRI or HindIII, and then ligated using T4 ligase. Ligation mixtures were used to transform E. coli TG1 repA ${ }^{+}$(a TG1 derivative with the repA gene integrated into the chromosome; P. Renault, INRA, Génétique Microbienne, Jouy-en-Josas, France). Transformants were selected by plating on Luria-Bertani (LB) medium containing $150 \mu \mathrm{g}$ erythromycin $\mathrm{ml}^{-1}$. Plasmid DNA of the transformants was extracted and sequenced using $\mathrm{pG}^{+}$host9:: ISS1-derived primers (Table 1). PG1 and PGHiIS were used for plasmids originating from HindIII

Table 1. Primers used in this study

\begin{tabular}{|ll|}
\hline Primer & \multicolumn{1}{c|}{ Sequence $\left(\mathbf{5}^{\prime} \mathbf{3}^{\prime}\right)$} \\
\hline PG1 & TGGCGAAAGGGGGATGTGCT \\
PG2 & ACTGACAGCTTCCAAGGA \\
PG3 & AGAATGTTACAGTCTATCC \\
PGHiIS & CTACTGAGATTAAGGTCT \\
PGEcoIS & ATAGTTCATTGATATATC \\
noxBF & GTCCTTTGTAAATTGAAC \\
noxB_XmaI_R & CCCCCGGGCAATGTTGATGAAGAATAT ${ }^{*}$ \\
noxA_XmaI_F & CCCCCGGGCACCTACAATAACGATT ${ }^{*}$ \\
cpoR & TCTCCGATTTTTCCAGC \\
sdaBF & ATTCGAGCAGCACCAGC \\
cpoR2 2 & TGATTTCAAACGCTATCG \\
menCF & TTAAGAAAAGAGCTCAAAGC \\
menCR & TGCGAAGTAAAATTCACTTG \\
\hline
\end{tabular}

${ }^{\star} \mathrm{XmaI}$ sites indicated by underlining. 
digestion and PG2 and PGEcoIS were used for plasmids originating from $E c o$ RI digestion. The sequences were compared with the genome of L. lactis MG1363 (Wegmann et al., 2007) using BLAST programs (Altschul et al., 1990) on the BLAST server (National Center for Biological Information, Bethesda, MD, USA) to identify interrupted genes.

pG ${ }^{+}$host9 : : ISS1 excision. A stable menC-negative mutant was obtained from the $\mathrm{pG}^{+}$host $9:$ :ISS1-inserted mutant $\Delta$ men $_{3}$ by plasmid excision, as described by Maguin et al. (1996). Excision of the $\mathrm{pG}^{+}$host $9:$ : ISS1 was confirmed by PCR. Two primers, one upstream (menCF) and one downstream (menCR) of the men $C$ gene, were used to amplify the corresponding genomic region. In the wild-type strain, the amplicon was $1276 \mathrm{bp}$ long, while it was $1987 \mathrm{bp}$ long in the excised mutant, because of the presence of ISS1 (711 bp). When the $\mathrm{pG}^{+}$host9: : ISS1 did not excise, there was no amplification.

Construction of a noxA-noxB negative mutant ( $\triangle$ noxAB). The nox $A$ and noxB genes were inactivated together in L. lactis TIL46 by double crossing-over, resulting in the $\triangle \operatorname{nox} A B$ mutant. Gene sequences were obtained from the published MG1363 sequence (Wegmann et al., 2007). An internal 848 bp DNA fragment of the noxB gene (F1), and an 852 bp DNA fragment of the downstream region of noxA (F2) were PCR-amplified with the noxBF and noxB_XmaI_R and the noxA_XmaI_F and cpoR primers, respectively (Table 1). The F1 and F2 fragments were introduced independently into the subcloning vector pGEM-T Easy (Promega). F1 was first digested with PstI and a blunt end was generated by the action of T4 DNA polymerase. F1 was subsequently digested by XmaI. F2 was digested by ApaI and XmaI and cloned into the thermosensitive vector $\mathrm{pG}^{+}$host9 (Maguin et al., 1992). This construction was then digested with XmaI and MslI to allow the cloning of F1 next to F2. The resulting $\mathrm{pG}^{+}$host 9 containing $\mathrm{F} 1$ and $\mathrm{F} 2$ was verified by PCR amplification with PG2 and PG3, and then transformed into TIL46 with erythromycin selection. After integration and excision of the plasmid by temperature shifts (Maguin et al., 1992), noxA-noxB inactivation was confirmed by sequencing with the sdaBF and cpoR2 primers (Table 1).

\section{Quantification of the TV reduction ability of $L$. lactis}

On a solid medium with growing cells (plate test). For each strain, $250 \mu \mathrm{l}$ of an overnight GM17 culture was plated on a MilkAgarTV plate. After incubation for $24 \mathrm{~h}$ at $30{ }^{\circ} \mathrm{C}$, formazan was quantified in both L. lactis cells and MilkAgarTV. L. lactis cells were swabbed from the surface of the MilkAgarTV three times using $2 \mathrm{ml}$ water. The optical density of the suspension was measured at 480 and $600 \mathrm{~nm}$. $L$. lactis cells from $4 \mathrm{ml}$ of the suspension were harvested by centrifugation ( $4000 \mathrm{~g}, 5 \mathrm{~min}$ ) and resuspended in $1 \mathrm{ml} \mathrm{DMSO}$ to solubilize the formazan. After centrifugation $(15000 \mathrm{~g}, 10 \mathrm{~min})$, the $A_{510}$ of the supernatant was measured (Uvikon XL spectrophotometer, Biotek Instruments, path length $1 \mathrm{~cm}$ ). The coloured MilkAgarTV was transferred to a $50 \mathrm{ml}$ tube, melted in a microwave $(2 \times 5 \mathrm{~s})$ and kept at $50{ }^{\circ} \mathrm{C}$. After homogenization, $30 \mathrm{ml} 100 \%$ ethanol was added to solubilize the formazan. After the mixture had been shaken and centrifuged (15000 $\mathrm{g}, 15 \mathrm{~min})$, the volume and $A_{510}$ of the supernatant were determined.

In a liquid medium with resting cells (liquid test). L. lactis cells from $2 \mathrm{ml}$ of the milk culture at $\mathrm{OD}_{480} 2$ were harvested by centrifugation $(4000 \mathrm{~g}, 5 \mathrm{~min})$ after solubilizing caseins with a $10^{-1}$-dilution in $100 \mathrm{mM}$ Tris buffer $\mathrm{pH} 8.0$ containing $20 \mathrm{~g}$ sodium citrate $\mathrm{l}^{-1}$. The cells, in a resting state, were resuspended in $4 \mathrm{ml}$ water. One millilitre of resting cells was immediately incubated for $15 \mathrm{~min}$ with $0.5 \mathrm{mM} \mathrm{TV}$, in the dark. The cells were then harvested by centrifugation $(15000 \mathrm{~g}$, $10 \mathrm{~min}$ ) and resuspended in $1 \mathrm{ml}$ DMSO to solubilize the formazan. After centrifugation ( $15000 \mathrm{~g}, 10 \mathrm{~min}$ ), the $A_{510}$ of the supernatant was measured. Another set of experiments was carried out using the same procedure as described above, but with the addition of $200 \mathrm{U}$ superoxide dismutase (SOD, Sigma) to the TV solution.

For quantification, a calibration curve was established with a TVformazan solution prepared as described by Smith \& McFeters (1997). Briefly, $5.2 \mathrm{mM}$ TV was reduced with $10 \mathrm{mM}$ sodium hydrosulfite. The precipitate was washed twice with MilliQ water and solubilized in DMSO or $95 \%$ ethanol. The absorption spectrum of the solutions showed a maximum at $510 \mathrm{~nm}$. The $A_{510}$ of TV-formazan solutions from 0 to $0.1 \mathrm{mM}$ was measured to draw the calibration curve. The slope of the curve was used to determine the amount of formazan in the samples.

Determination of the intracellular NADH concentration of cells grown in milk. The intracellular $\mathrm{NADH}$ concentration was determined using an in vitro procedure based on the rapid inactivation of cell metabolism followed by direct NADH extraction from culture samples, and measurement by HPLC. The selected mutants were grown in skimmed milk (Lescure) until the culture reached an $\mathrm{OD}_{480}$ of 2 . Culture samples of $5 \mathrm{ml}$ were immediately frozen in liquid nitrogen and stored at $-80{ }^{\circ} \mathrm{C}$. NADH was extracted as described by Lebloas et al. (1993) and Garrigues et al. (1997). A variable volume $(100-200 \mu \mathrm{l})$ of $10 \mathrm{M} \mathrm{KOH}$ was added to the culture samples during thawing to obtain a final $\mathrm{pH}$ of 12.5. For each culture, two samples were treated with $\mathrm{KOH}$. Fifteen microlitres of $1 \mathrm{mM}$ $\mathrm{NADH}$ in DMSO was added to one sample while the same volume of DMSO was added to the second sample. The $\mathrm{KOH}$-treated cultures were incubated for $10 \mathrm{~min}$ at room temperature. After centrifugation $\left(15000 \mathrm{~g}, 10 \mathrm{~min}, 4{ }^{\circ} \mathrm{C}\right)$, the supernatant was cleared of proteins using an Ultrafree- 0.5 centrifugal filter device consisting of a Biomax membrane with a $10 \mathrm{kDa}$ molecular mass cut-off point (Millipore). The amount of $\mathrm{NADH}$ in the ultrafiltrate was immediately determined by ion-pairing HPLC, as described by Ganzera et al. (2006). Briefly, the HPLC system (Waters) consisted of a 717 plus autosampler, a 600 quaternary pump, a 486 UV detector and Millennium software. Determination of the quantity of NADH in samples took account of the percentage recovery of NADH added to each sample, which was around $75 \%$.

\section{RESULTS}

\section{Selection of TIL46 mutants affected in their ability to reduce TV on MilkAgarTV and identification of interrupted genes}

MilkAgarTV screening of the 8544-mutant library constructed in L. lactis TIL46 revealed 30 mutants with TV reduction abilities that differed from those of the WT strain TIL46. Individual plating of the 30 mutants on MilkAgarTV and MilkAgarBP media confirmed six mutants that were actually affected regarding TV reduction, the others being affected in their growth. Five of the six selected mutants did not reduce TV, and one reduced TV more than the WT (Fig. 1).

Sequencing of the DNA regions in which $\mathrm{pG}^{+}$host $9::$ ISS1 was integrated in the five non-reducing mutants showed that the disrupted genes were all involved in menaquinone biosynthesis. The inactivated genes were menB in one mutant and $m e n C$ in the four others. In the high-reducing mutant, the interrupted gene was $l d h$, encoding lactate dehydrogenase.

The results were confirmed using TIL380, a TIL46 ldhnegative mutant (Chambellon et al., 2009) and the menC- 


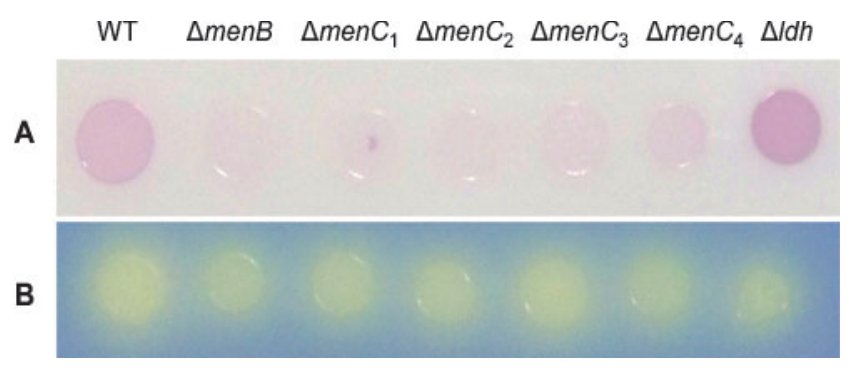

Fig. 1. Plate tests of TIL46 (wild-type strain, WT) and selected mutants from the library screening: (A) on MilkAgarTV; (B) on MilkAgarBP.

negative mutant from which $\mathrm{pG}^{+}$host 9 : : ISS 1 was excised. These two stable mutants were named $\Delta l d h$ and $\Delta m e n C$ and used for further experiments.

To complete this mutant selection, we constructed a mutant inactivated for the membrane NADH dehydrogenases NoxA and NoxB $(\triangle$ nox $A B)$, since they are thought to be involved in the reduction of menaquinones in L. lactis (Gaudu et al., 2002; Melo et al., 2004). When spotted on MilkAgarTV, this mutant reduced TV less than the WT strain (Fig. 2, picture).

\section{TV reduction by growing cells on solid medium}

Each strain, i.e. WT, $\Delta l d h, \Delta m e n C$ and $\Delta$ nox $A B$, was spread and grown on a MilkAgarTV plate. After incubation for $24 \mathrm{~h}$ at $30{ }^{\circ} \mathrm{C}, \mathrm{L}$. lactis cells totally covered the MilkAgarTV and displayed the same visual TV reduction as when spotted (Fig. 2). The strains were ranked from the most reducing to the least reducing as follows: $\Delta l d h$, WT and $\triangle$ noxAB. $\triangle m e n C$ did not reduce MilkAgarTV. In order to quantify formazan, L. lactis cells were recovered from MilkAgarTV. The cell suspension was coloured in the case of WT, $\Delta l d h$ and $\Delta$ noxAB, but not for $\Delta m e n C$. It is noteworthy that a considerable amount of formazan remained in the upper part of MilkAgarTV plates after the WT, $\Delta l d h$ and $\Delta$ noxAB cells had been removed. No

$\begin{array}{lllll} & \text { WT } & \Delta l d h & \Delta \operatorname{mox} A B & \Delta \text { menC } \\ & & & & \\ & & & & \\ \text { L.lactis cells } & 45 \pm 8 & 104 \pm 13^{\star \star \star} & 27 \pm 1^{\star} & 7 \pm 1^{* \star *} \\ \text { Agar } & 144 \pm 33 & 189 \pm 27^{\star \star *} & 69 \pm 12^{\star \star} & \text { IS } \\ \text { Total } & 188 \pm 26 & 293 \pm 38^{\star \star \star} & 96 \pm 11^{\star \star \star} & \text { IS }\end{array}$

Fig. 2. Amounts of formazan obtained from plated cultures. The quantities of formazan determined in swabbed cells and in agar fractions are given in nmoles (means $\pm S D ; n=3$ ). IS, insignificant amount of formazan. Student's $t$ test between data for WT and mutants: ${ }^{*}, P<0.05 ;{ }^{* \star}, P<0.01 ;{ }^{\star \star \star}, P<0.001$. formazan was observed deeper in the medium, indicating that TV reduction occurred on the surface of MilkAgarTV. Formazan was quantified both in L. lactis cells and in the coloured part of MilkAgarTV for the four strains. In the case of L. lactis, formazan was strongly associated with the cells. Indeed, after centrifugation, the bacterial pellets were coloured, while the supernatant was colourless. Moreover, we failed to solubilize formazan from cells using $95 \%$ ethanol, even after sonication and shaking for one night. Only DMSO, which is known to partially solubilize cell membranes, was able to solubilize formazan. In the case of MilkAgarTV, formazan included in the agar was easily solubilized with ethanol, suggesting that it had been produced outside the cell and precipitated close to the bacteria. The quantification of formazan contained in both L. lactis cells and MilkAgarTV revealed that $65-75 \%$ of total formazan was localized in MilkAgarTV (Fig. 2). The total production of formazan by L. lactis TIL46 was decreased by $50 \%$ by NoxAB inactivation $(P<0.001)$, while it was almost totally suppressed by MenC inactivation. By contrast, formazan production increased 1.6-fold when LDH was inactivated $(P<0.001)$. The addition of SOD to the medium had no effect on TV reduction, indicating that the reduction did not involve superoxide ions.

\section{TV reduction by resting cells in liquid medium}

WT, $\Delta l d h, \Delta m e n C$ and $\triangle n o x A B$ cells from milk cultures were incubated in an aqueous TV solution (liquid medium). TV reduction was rapid, and a maximum of 15 min was sufficient for the reaction to be completed. All the formazan thus formed pelleted with cells after centrifugation, while the supernatants were colourless. Attempts to solubilize formazan from the cell pellet using $95 \%$ ethanol failed, even after sonication, treatment with lysozyme $\left(30 \mathrm{mg} \mathrm{ml}^{-1}\right)$ and Triton ( $\left.2 \%\right)$. Only DMSO was able to solubilize formazan from $L$. lactis cells, suggesting that formazan was inside the cell membranes. Fig. 3 shows the amount of formazan formed by each strain. Formazan production by the WT was increased threefold by LDH inactivation $(P<0.001)$. Surprisingly, it was only partly affected by MenC inactivation $(P<0.05)$, while it was almost totally suppressed by NoxAB inactivation $(P<0.001)$. The results of these liquid tests differed markedly from those observed with the plate test, especially in the case of MenC and NoxAB inactivations. In no cases did the addition of SOD affect TV reduction.

\section{NADH pool in the selected mutants}

To verify that an increase in TV reduction was related to a larger intracellular NADH pool, this pool was quantified in milk cultures (Fig. 4). The NADH pool was threefold larger when LDH was inactivated compared to WT $(P<0.001)$, while it was not affected by MenC inactivation $(P>0.05)$ and only slightly increased by NoxAB inactivation $(P>0.05)$. 


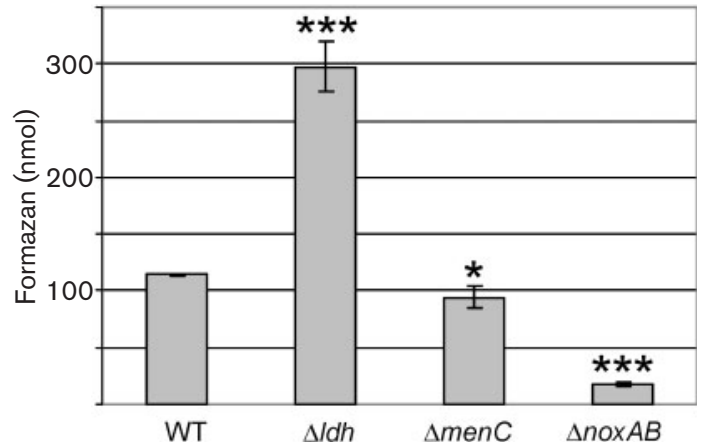

Fig. 3. Amounts of formazan formed by $L$. lactis cells recovered from $1 \mathrm{ml}$ of milk culture with an $\mathrm{OD}_{480}$ of 2 , after incubation for $15 \mathrm{~min}$ in an $0.5 \mathrm{mM}$ TV solution. Data are means \pm SD $(n=3)$. Student's $t$ test between data for WT and mutants: * $P<0.05$; ${ }^{* \star *}$, $P<0.001$.

\section{DISCUSSION}

Although it is assumed that tetrazolium salts are reduced by electrons originating from intracellularly metabolized substrates via the ETC, the sites of reduction in the chain are not clearly established in bacteria. Using a mutagenesis approach, we determined the sites of TV reduction in $L$. lactis, using both a plate test with growing cells and a liquid test with resting cells. In both cases, we showed that the ETC was actually involved in TV reduction by L. lactis, but the sites of reduction depended on the experimental conditions. The essential factors for TV reduction were menaquinones in the plate test with growing cells, and the $\mathrm{NADH}$ dehydrogenases NoxA and/or NoxB in the liquid test with resting cells.

In the plate test, menaquinones appeared to be the sole site of TV reduction, as no reduction occurred when MenB or MenC were inactive. Moreover, TV reduction by menaquinones did not involve an extracellular superoxide

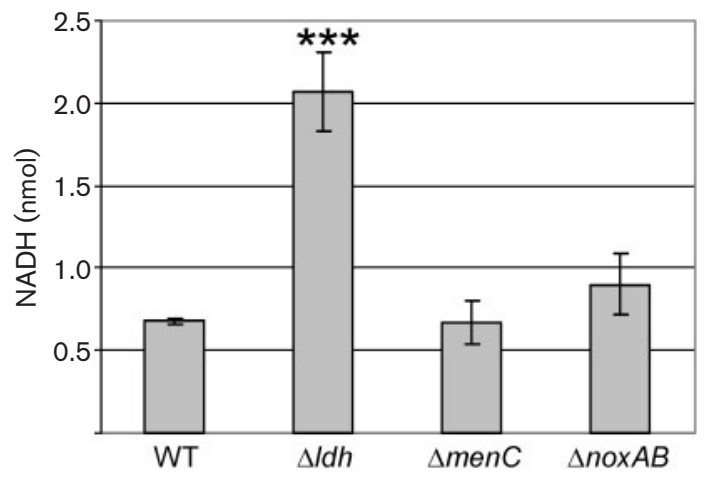

Fig. 4. $\mathrm{NADH}$ pool in L. lactis cells of $1 \mathrm{ml}$ of milk culture with an $\mathrm{OD}_{480}$ of 2. Data are means $\pm \mathrm{SD}(n=3)$. Student's $t$ test between data for WT and mutants: ${ }^{\star \star *}, P<0.001$. intermediate, as the addition of superoxide dismutase did not affect reduction. Similarly, menaquinones have been shown to reduce $\mathrm{Cu}^{2+}$ directly, while they reduced $\mathrm{Fe}^{3+}$ via the superoxide produced from oxygen reduction (Rezaiki et al., 2008). Menaquinones that reduced TV appeared to be partially reduced by the membrane NADH dehydrogenases NoxA and/or NoxB, as NoxAB inactivation led to a $50 \%$ decrease in TV reduction; thus another membrane dehydrogenase has to be responsible for the other $50 \%$ contribution to menaquinone reduction. Succinate dehydrogenase, also called fumarate reductase (FRD), is a component of the ETC in E. coli but seems to be lacking in $L$. lactis. Only the $f r d C$ gene, which encodes the FRD flavoprotein subunit, was found in the genome (Wegmann et al., 2007), ruling out a role for FRD in menaquinone reduction in L. lactis. According to Gaudu et al. (2002), the membrane glycerol-3-phosphate reductase GlpD may be the alternative dehydrogenase. Since NoxA and/or NoxB transfer electrons from the intracellular $\mathrm{NADH}$ pool to menaquinones, a larger intracellular pool of NADH in $\Delta l d h$ could explain the greater capacity of this strain to reduce TV. In agreement with the $50 \%$ contribution of NoxA and/or NoxB to menaquinone reduction, a threefold increase in the NADH pool led to about a 1.5 -fold increase in TV reduction by $\Delta l d h$. Fig. 5(A) shows a schematic representation of the TV reduction mechanism in the plate test with growing cells.

In the liquid test, in contrast to the plate test, NoxA and/or NoxB appeared to be the principal site of TV reduction. Indeed, NoxAB inactivation suppressed $85 \%$ of TV reduction, while MenC inactivation only decreased TV reduction by $15 \%$. In $\triangle$ nox $A B$, the menaquinones that are responsible for residual TV reduction are probably reduced by the other membrane dehydrogenase (GlpD). This dehydrogenase appeared to be unable to reduce TV directly, otherwise $\triangle$ nox $A B$ would have been able to reduce more TV. Under these experimental conditions, and since NoxA and/or NoxB were almost totally responsible for TV reduction, reduction was proportional to the NADH pool. Indeed, a threefold increase in the NADH pool in $\Delta l d h$ led to a threefold increase in TV reduction. Fig. 5(B) shows a schematic representation of the TV reduction mechanism in the liquid test with resting cells.

These different reduction sites in the ETC under both experimental conditions are probably linked to the cellular localization of TV reduction. In the liquid test, TV reduction occurred entirely in the cell membrane, probably in the inner part where NoxA and NoxB are localized. In the plate test, we observed that $65-75 \%$ of TV reduction occurred outside the cell, and only $25-35 \%$ in the cell membrane, probably in the outer part because NoxA and/ or NoxB did not reduce TV directly. In both tests, there was no evidence of intracellular reduction by cytoplasmic dehydrogenases. Indeed, formazan was not released after cell breakdown due to chemical, mechanical or enzymic treatments. The localization of TV reduction is probably affected by the different ability of TV to enter cells under 
A

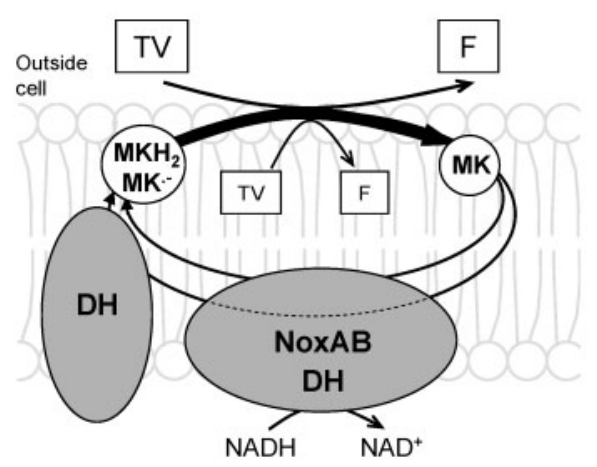

B

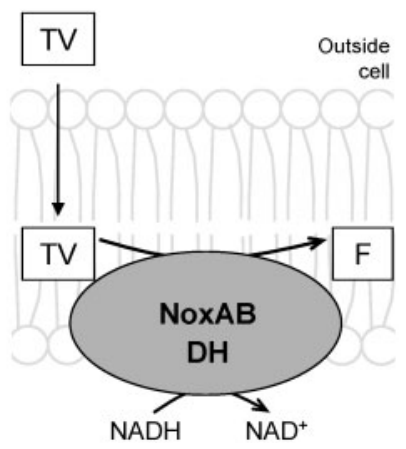

Fig. 5. Schematic representation of the mechanism of TV reduction: $(A)$ in the plate test with growing cells; $(B)$ in the liquid test with resting cells. TV, tetrazolium violet; F, formazan; MK, oxidized menaquinones; $\mathrm{MK}^{-}{ }^{-}$, semiquinones; $\mathrm{MKH}_{2}$, reduced menaquinones; NoxAB DH, membrane $\mathrm{NADH}$ dehydrogenases NoxA and NoxB; $\mathrm{DH}$, dehydrogenase. the two conditions. Both the nature of the growth medium (liquid vs solid) and the physiological state of bacteria (growing vs resting) could affect the cell permeability of TV. On the one hand, the mobility of nutrient ions and other soluble molecules is known to be higher in liquid media (Miller \& Davey, 1965); on the other hand, the passive diffusion of hydrophobic molecules may be greater in resting cells than in growing cells.

Contrary to what we had expected, the reduction sites identified here for TV could not be generalized to all other positively charged salts. MTT, TTC and INT reduction by the four selected strains (WT, $\Delta l d h, \Delta m e n C$ and $\Delta$ noxAB) was tested on plates and only the results with TTC were the same as those with TV, although the coloration was weaker. MTT was markedly reduced by all strains and INT was similarly reduced by all strains except $\triangle$ nox $A B$, where reduction was only partial. Because of the chemical differences between salts, it is not possible to predict the reduction of different tetrazolium salts by the same strain, even if they are all positively charged.

New applications for tetrazolium tests could be based on the conclusions of this study. Firstly, we demonstrated that tests with tetrazolium salts, and especially TV, could be used for studies of LAB despite their acidifying property. In L. lactis, the TV plate test could be used to screen mutants affected in menaquinone biosynthesis. This application could be extended to other LAB in order to distinguish species that produce menaquinones from those that do not. The TV reduction test in liquid medium could be useful to estimate the NADH pool in cells. This method could facilitate studies of the impact of different growth conditions or gene inactivation on the NADH pool. Indeed, the TV reduction test in a liquid medium is simple, rapid and inexpensive when compared to the standard methods used to measure NADH in bacteria, which require special equipment, are often difficult to perform and are very time-consuming (Ganzera et al., 2006; Garrigues et al., 1997; Lebloas et al., 1993).

To conclude, using a mutagenesis approach, we have demonstrated that the ETC sites of TV reduction by L. lactis are membrane $\mathrm{NADH}$ dehydrogenases in a liquid test and menaquinones in a plate test. Similar studies using other tetrazolium salts will be necessary to understand the differences in reduction capacity observed between tetrazolium salts.

\section{ACKNOWLEDGEMENTS}

This work was supported by a Eureka Research grant ( $\Sigma$ !3562LABREDOX). We are grateful to CSK Food Enrichment for their financial support. We thank Véronique Monnet (INRA) and Hans Brandsma (CSK Food Enrichment) for their critical reading of the manuscript.

\section{REFERENCES}

Altschul, S. F., Gish, W., Miller, W., Myers, E. W. \& Lipman, D. J. (1990). Basic local alignment search tool. J Mol Biol 215, 403-410.

Beloti, V., Barros, M. A. F., de Freitas, J. C., Nero, L. A., de Souza, J. A., Santana, E. H. W. \& Franco, B. D. G. M. (1999). Frequency of 2,3,5triphenyltetrazolium chloride (TTC) non-reducing bacteria in pasteurized milk. Rev Microbiol 30, 137-140.

Bernas, T. \& Dobrucki, J. (1999). Reduction of a tetrazolium salt, CTC, by intact HepG2 human hepatoma cells: subcellular localisation of reducing systems. Biochim Biophys Acta 1451, 73-81.

Bernas, T. \& Dobrucki, J. W. (2000). The role of plasma membrane in bioreduction of two tetrazolium salts, MTT, and CTC. Arch Biochem Biophys 380, 108-116.

Bernas, T. \& Dobrucki, J. (2002). Mitochondrial and nonmitochondrial reduction of MTT: interaction of MTT with TMRE, JC-1, and NAO mitochondrial fluorescent probes. Cytometry 47, 236-242.

Bernas, T. \& Dobrucki, J. W. (2004). Backscattered light confocal imaging of intracellular MTT-formazan crystals. Microsc Res Tech 64, 126-134.

Berridge, M. V. \& Tan, A. S. (1993). Characterization of the cellular reduction of 3-(4,5-dimethylthiazol-2-yl)-2,5-diphenyltetrazolium bromide (MTT): subcellular localization, substrate dependence, and involvement of mitochondrial electron transport in MTT reduction. Arch Biochem Biophys 303, 474-482.

Berridge, M. V., Herst, P. M. \& Tan, A. S. (2005). Tetrazolium dyes as tools in cell biology: new insights into their cellular reduction. In Biotechnology Annual Review, pp. 127-152. Edited by M. R. ElGewely. Amsterdam: Elsevier.

Bhupathiraju, V. K., Hernandez, M., Landfear, D. \& Alvarez-Cohen, L. (1999). Application of a tetrazolium dye as an indicator of viability in anaerobic bacteria. J Microbiol Methods 37, 231-243. 
Bochner, B. R. (1989). Sleuthing out bacterial identities. Nature 339, 157-158.

Bochner, B. R. \& Savageau, M. A. (1977). Generalized indicator plate for genetic, metabolic, and taxonomic studies with microorganisms. Appl Environ Microbiol 33, 434-444.

Bochner, B. R., Gadzinski, P. \& Panomitros, E. (2001). Phenotype microarrays for high-throughput phenotypic testing and assay of gene function. Genome Res 11, 1246-1255.

Bochner, B. R., Giovannetti, L. \& Viti, C. (2008). Important discoveries from analysing bacterial phenotypes. Mol Microbiol 70, 274-280.

Bolotin, A., Wincker, P., Mauger, S., Jaillon, O., Malarme, K., Weissenbach, J., Ehrlich, S. D. \& Sorokin, A. (2001). The complete genome sequence of the lactic acid bacterium Lactococcus lactis ssp. lactis IL1403. Genome Res 11, 731-753.

Brasca, M., Morandi, S., Lodi, R. \& Tamburini, A. (2007). Redox potential to discriminate among species of lactic acid bacteria. J Appl Microbiol 103, 1516-1524.

Brooijmans, R. J., Poolman, B., Schuurman-Wolters, G. K., de Vos, W. M. \& Hugenholtz, J. (2007). Generation of a membrane potential by Lactococcus lactis through aerobic electron transport. J Bacteriol 189, 5203-5209.

Chambellon, E., Rijnen, L., Lorquet, F., Gitton, C., van Hylckama Vlieg, J. E., Wouters, J. A. \& Yvon, M. (2009). The D-2-hydroxyacid dehydrogenase incorrectly annotated PanE is the sole reduction system for branched-chain 2-keto acids in Lactococcus lactis. J Bacteriol 191, 873-881.

Ganzera, M., Vrabl, P., Worle, E., Burgstaller, W. \& Stuppner, H. (2006). Determination of adenine and pyridine nucleotides in glucose-limited chemostat cultures of Penicillium simplicissimum by one-step ethanol extraction and ion-pairing liquid chromatography. Anal Biochem 359, 132-140.

Garrigues, C., Loubière, P., Lindley, N. D. \& Cocaign-Bousquet, M. (1997). Control of the shift from homolactic acid to mixed-acid fermentation in Lactococcus lactis: predominant role of the NADH/ $\mathrm{NAD}^{+}$ratio. J Bacteriol 179, 5282-5287.

Gaudu, P., Vido, K., Cesselin, B., Kulakauskas, S., Tremblay, J., Rezaiki, L., Lamberret, G., Sourice, S., Duwat, P. \& Gruss, A. (2002). Respiration capacity and consequences in Lactococcus lactis. Antonie Van Leeuwenhoek 82, 263-269.

Griebe, T., Schaule, G. \& Wuertz, S. (1997). Determination of microbial respiratory and redox activity in activated sludge. $J$ Ind Microbiol Biotechnol 19, 118-122.

Hayashi, S., Kobayashi, T. \& Honda, H. (2003). Simple and rapid cell growth assay using tetrazolium violet coloring method for screening of organic solvent tolerant bacteria. J Biosci Bioeng 96, 360-363.

Herst, P. M., Perrone, G. G., Dawes, I. W., Bircham, P. W. \& Berridge, M. V. (2008). Plasma membrane electron transport in Saccharomyces cerevisiae depends on the presence of mitochondrial respiratory subunits. FEMS Yeast Res 8, 897-905.

Holo, H. \& Nes, I. F. (1989). High-frequency transformation, by electroporation, of Lactococcus lactis subsp. cremoris grown with glycine in osmotically stabilized media. Appl Environ Microbiol 55, 3119-3123.

Lebloas, P., Guilbert, N., Loubière, P. \& Lindley, N. D. (1993). Growth inhibition and pyruvate overflow during glucose metabolism of Eubacterium limosum are related to a limited capacity to reassimilate $\mathrm{CO}_{2}$ by the acetyl-CoA pathway. J Gen Microbiol 139, 1861-1868.

Lin, Y. C., Agbanyim, C. N., Miles, R. J., Nicholas, R. A., Kelly, D. P. \& Wood, A. P. (2008). Tetrazolium reduction methods for assessment of substrate oxidation and strain differentiation among mycoplasmas, with particular reference to Mycoplasma bovigenitalium and some members of the Mycoplasma mycoides cluster. J Appl Microbiol 105, 492-501.
Maguin, E., Duwat, P., Hege, T., Ehrlich, D. \& Gruss, A. (1992). New thermosensitive plasmid for gram-positive bacteria. J Bacteriol 174, 5633-5638.

Maguin, E., Prevost, H., Ehrlich, S. D. \& Gruss, A. (1996). Efficient insertional mutagenesis in lactococci and other gram-positive bacteria. J Bacteriol 178, 931-935.

Melo, A. M., Bandeiras, T. M. \& Teixeira, M. (2004). New insights into type II NAD(P)H:quinone oxidoreductases. Microbiol Mol Biol Rev 68, 603-616.

Miller, R. J. \& Davey, C. B. (1965). Influence of the microphysical structure of a system on the growth of bacteria. Can J Microbiol 11, 761-763.

Morishita, T., Tamura, N., Makino, T. \& Kudo, S. (1999). Production of menaquinones by lactic acid bacteria. J Dairy Sci 82, 1897-1903.

O’Sullivan, D. J. \& Klaenhammer, T. R. (1993). Rapid mini-prep isolation of high-quality plasmid DNA from Lactococcus and Lactobacillus spp. Appl Environ Microbiol 59, 2730-2733.

Raut, U., Narang, P., Mendiratta, D., Narang, R. \& Deotale, V. (2008). Evaluation of rapid MTT tube method for detection of drug susceptibility of Mycobacterium tuberculosis to rifampicin and isoniazid. Indian J Med Microbiol 26, 222-227.

Rezaiki, L., Lamberet, G., Derre, A., Gruss, A. \& Gaudu, P. (2008). Lactococcus lactis produces short-chain quinones that cross-feed Group B Streptococcus to activate respiration growth. Mol Microbiol 67, 947-957.

Rodriguez, G. G., Phipps, D., Ishiguro, K. \& Ridgway, H. F. (1992). Use of a fluorescent redox probe for direct visualization of actively respiring bacteria. Appl Environ Microbiol 58, 1801-1808.

Sambrook, J. \& Russell, D. W. (2001). Molecular Cloning: a Laboratory Manual, 3rd edn. Cold Spring Harbor, NY: Cold Spring Harbor Laboratory.

Smit, B. A., van Hylckama Vlieg, J. E., Engels, W. J., Meijer, L., Wouters, J. T. \& Smit, G. (2005). Identification, cloning, and characterization of a Lactococcus lactis branched-chain alpha-keto acid decarboxylase involved in flavor formation. Appl Environ Microbiol 71, 303-311.

Smith, J. J. \& McFeters, G. A. (1997). Mechanisms of INT (2-(4iodophenyl)-3-(4-nitrophenyl)-5-phenyl tetrazolium chloride), and CTC (5-cyano-2,3-ditolyl tetrazolium chloride) reduction in Escherichia coli K-12. J Microbiol Methods 29, 161-175.

Sollod, C. C., Jenns, A. E. \& Daub, M. E. (1992). Cell surface redox potential as a mechanism of defense against photosensitizers in fungi. Appl Environ Microbiol 58, 444-449.

Tsukatani, T., Suenaga, H., Higuchi, T., Akao, T., Ishiyama, M., Ezoe, K. \& Matsumoto, K. (2008). Colorimetric cell proliferation assay for microorganisms in microtiter plate using water-soluble tetrazolium salts. J Microbiol Methods 75, 109-116.

Tunney, M. M., Ramage, G., Field, T. R., Moriarty, T. F. \& Storey, D. G. (2004). Rapid colorimetric assay for antimicrobial susceptibility testing of Pseudomonas aeruginosa. Antimicrob Agents Chemother 48, 1879-1881.

Turner, N., Sandine, W. E., Elliker, P. R. \& Day, E. A. (1963). Use of tetrazolium dyes in an agar medium for differentiation of Streptococcus lactis and Streptococcus cremoris. J Dairy Sci 46, 380-385.

Wegmann, U., O'Connell-Motherway, M., Zomer, A., Buist, G., Shearman, C., Canchaya, C., Ventura, M., Goesmann, A., Gasson, M. J. \& other authors (2007). Complete genome sequence of the prototype lactic acid bacterium Lactococcus lactis subsp. cremoris MG1363. J Bacteriol 189, 3256-3270.

Edited by: V. Eijsink 